\title{
Real-World Prescribing Pattern of Asthma Management in China: A Retrospective, Descriptive Analysis
}

\section{Jian Sun}

Department of Pulmonary and Critical Care Medicine, Shandong Provincial Hospital, Cheeloo College of Medicine, Shandong University, Jinan

\section{Xin Wang}

Department of Pulmonary and Critical Care Medicine, Jinan Central Hospital, Cheeloo College of Medicine, Shandong University, Jinan

\section{Xiaobin Ma}

Department of Pulmonary and Critical Care Medicine, Shandong Provincial Hospital, Cheeloo College of Medicine, Shandong University, Jinan

\section{Yuyu Feng}

Department of Pulmonary and Critical Care Medicine, Jinan Shizhong People's Hospital, Jinan

\section{Yajun Wang}

Department of Pulmonary and Critical Care Medicine, Shandong Provincial Hospital affiliated to Shandong First Medical University, Jinan

\section{Junren Wang}

Department of Pulmonary and Critical Care Medicine, Shandong Provincial Hospital affiliated to Shandong First Medical University, Jinan

Shujuan Jiang ( $\sim$ docjiangshujuan@163.com )

Department of Pulmonary and Critical Care Medicine, Shandong Provincial Hospital, Cheeloo College of Medicine, Shandong University, Jinan

\section{Chunyan Xing}

Department of Pulmonary and Critical Care Medicine, Jinan Central Hospital, Cheeloo College of Medicine, Shandong University, Jinan

\section{Research Article}

Keywords: Asthma exacerbation, Inhaled corticosteroids, Traditional Chinese medicine, Pulmonary diseases

Posted Date: January 10th, 2022

DOI: https://doi.org/10.21203/rs.3.rs-1158031/v2

License: (9) (1) This work is licensed under a Creative Commons Attribution 4.0 International License. Read Full License 


\section{Abstract \\ Background}

Asthma is a chronic inflammatory disorder of the airway that requires long-term medication management.

\section{Objective}

To describe the real-world prescribing patterns for asthma management in the Chinese population.

\section{Methods}

A retrospective analysis of 8,732 patients from January 2011 to September 2019 in 10 hospitals was conducted. Prescribing patterns of short-acting beta-agonists (SABA), long-acting beta-agonists (LABA), inhaled corticosteroids (ICS), intravenous corticosteroids, antihistamines, leukotriene receptor antagonists (LTRA), theophylline, antibiotics, and Chinese patent medicines were included in the analysis. Chi-square and logistic regression were calculated. $P$ value of $<0.05$ was considered as statistical significance.

\section{Results}

ICS/LABA were prescribed for 2,940 (33.67\%) patients with stable asthma and 141 (31.4\%) patients with asthma exacerbations. LTRA was prescribed in 2,006 (22.97\%) patients with stable asthma, and $86(19.15 \%)$ patients with asthma exacerbations. Systemic antibiotics $(46.1 Z \%)$, systemic corticosteroids (57.91\%), and theophylline (51.45\%) were frequently prescribed during exacerbations. A total of 5,766 patients (64.95\%) were managed with traditional Chinese medication (TCM); 3237 patients (36.47\%) received western medicine. Patients using ICS/LABA $(P=0.019)$ and SABA $(P=0.008)$ had a significantly lower rate of asthma exacerbations.

\section{Conclusions}

This study provides valuable insight into clinical practices of asthma management in China. Poor adherence to clinical reports was identified. Efforts are required to improve the quality of asthma care.

\section{Background}

Asthma is a chronic inflammatory disease of the airway presented with episodes of wheezing, shortness of breath, chest tightness[1-3]. Over 300 million people suffer from asthma worldwide, causing about 461,000 deaths per year[4,5]. A recent epidemiology study pointed out that about 45.7 million people in China have asthma, $28.8 \%$ of which were physician diagnosed[6]. Asthma poses a significant burden on the lives of patients and healthcare systems. An analysis of the UK national databases revealed that asthma resulted in 93,000 hospitalizations and 1,800 intensive-care unit visits[7]. The average asthma cost, varied from country to country, is $\$$ USD 1,900 to \$USD3,100. The cost is much higher in patients with severe, uncontrolled asthmas, or asthma exacerbations[8, 9].

Asthma exacerbations are commonly triggered by viral/bacterial infections, allergen exposure, and tobacco smoke[10]. It is presented as episodes of progressive increase in signs and symptoms, often leading to emergency department (ED) visits and hospital admissions. Therefore, proper asthma management and optimizing asthma medications are essential to alleviate the disease burden and economic burden on asthma patients. Inhale corticosteroids (ICS) remain the cornerstone of asthma treatment due to their efficacy in lowering risks of airway inflammations, exacerbations, and decline in lung function[11, 12]. The 2021 Global Initiative for Asthma (GINA) Report recommends ICS-formoterol as the preferred therapy in adult patients with mild asthma while using short-acting beta-agonist (SABA) alone is considered as an alternative[13]. Maintenance long-acting beta-agonists (LABA) are considered as part of the preferred therapy to whose asthma cannot be controlled with as-needed ICS/LABA[13, 14].

Several studies regarding the real-world pharmacological management of asthma mainly focused on the effectiveness of different types of inhalers, the risk of exacerbations in asthma of different severities, the choices of medications when initiating asthma treatment, and patient adherence to asthma medications[15-18]. Few research described the different prescribing patterns for asthma between traditional Chinese medication TCM and western medicine, well and poorly controlled asthma, as well as changes in the number of medications prescribed over the past decade. Whether these factors are associated with the risk of acute asthma exacerbations is still unclear. 
This study used longitudinal data of an asthma cohort from 10 hospitals in Jinan, China. The primary objective was to describe the realworld prescribing patterns for asthma management.

\section{Methods}

\section{Study Design}

This was a retrospective, descriptive analysis of patients over the age of 18 with at least one diagnosis of asthma from January 2011 to September 2019 in 10 hospitals. Patients were excluded if they had missing data for age or had surgical interventions during the same office visit. Data were extracted through a review of medical encounters documented in the Jinan Health Medical Big Data Platform, administered by Shandong Health Medical Big Data Co., Ltd.

\section{Clinical data and definitions}

Medications considered as parts of asthma regimens were short-acting beta-agonists (SABA), long-acting beta-agonists (LABA), inhaled corticosteroids (ICS), intravenous corticosteroids, antihistamines, leukotriene receptor antagonists (LTRA), theophylline, antibiotics, and Chinese patent medicines. Treatments using TCM were defined as any visit with prescription of Chinese medicine or proprietary Chinese medicine preparations to traditional Chinese medicine hospitals, department of TCM in tertiary hospitals, and/or department of TCM and integrative medicine in medical institutions. All other office visits were considered as western medicine treatments.

\section{Primary Endpoint}

The primary endpoint of the study is the proportion of different classes of asthma prescriptions. differences between western and Chinese medicine, stable asthma and acute asthma exacerbations, and yearly changes of asthma prescriptions were analyzed.

\section{Statistical analysis}

The counts and proportion of prescriptions in different aspects were calculated. The statistical analysis was conducted with R software, version 3.3.3 (R Foundation for Statistical Computing).

\section{Results}

\section{Medication use during the study period}

During the study period, 14,264 patients with asthma were identified, of which 8,789 patients had prescription-filling records. A total of 8,732 patients had prescriptions for stable asthma; 499 patients had prescriptions for acute asthma exacerbations. Classes of medications prescribed are presented in Table 1. A total of 1,192 ICS prescriptions were documented in 698 (7.99\%) patients with stable asthma and 160 prescriptions in 105 patients had asthma exacerbations. ICS/LABA was prescribed for 2,940 (33.67\%) patients with stable asthma and 141 (31.4\%) patients with asthma exacerbations, respectively. LTRA was prescribed in 2,006 (22.97\%) patients with stable asthma and 86 (19.15\%) patients with asthma exacerbations. Chinese herbal medicines or Chinese patent medicines were used in over $40 \%$ of patients with stable asthma and over $30 \%$ of patients with asthma exacerbations. Systemic antibiotics (57.91\%), systemic corticosteroids (46.1\%), and theophylline (51.45\%) were three of the top medications prescribed during acute asthma exacerbations. 
Table 1

Medication use in all patients with asthma

\begin{tabular}{|c|c|c|c|c|}
\hline & \multicolumn{2}{|l|}{ Stable Asthma } & \multicolumn{2}{|c|}{ Acute Asthma Exacerbations } \\
\hline & No. of patients & No. of prescriptions & No. of patients & No. of prescriptions \\
\hline Patient Numbers & 8,732 & $23,617^{a}$ & 449 & 981 \\
\hline Total ICS Prescriptions & 698(7.99) & 1,192 & $105(23.39 \%)$ & 160 \\
\hline ICS combination therapy ${ }^{a}$ & $19(0.22 \%)$ & 22 & $32(7.13 \%)$ & 33 \\
\hline ICS monotherapy & $681(7.8 \%)$ & 1170 & $78(17.37 \%)$ & 127 \\
\hline ICS/LABA & $2,940(33.67 \%)$ & 5,955 & $141(31.4 \%)$ & 174 \\
\hline LAMA & $83(0.95 \%)$ & 138 & $8(1.78 \%)$ & 11 \\
\hline LABA & $8(0.09 \%)$ & 8 & $3(0.67 \%)$ & 3 \\
\hline SABA & $703(8.05 \%)$ & 1,338 & $95(21.26 \%)$ & 153 \\
\hline SAMA & $45(0.52 \%)$ & 106 & $5(1.11 \%)$ & 6 \\
\hline SAMA+SABA & $41(0.47 \%)$ & 54 & $21(4.68 \%)$ & 27 \\
\hline Theophylline IR & $236(2.7 \%)$ & 386 & $231(51.45 \%)$ & 636 \\
\hline Theophylline SR & $16(0.18 \%)$ & 37 & $3(0.67 \%)$ & 3 \\
\hline Theophylline IV & $0(0 \%)$ & 0 & $228(50.78 \%)$ & 631 \\
\hline LTRA & $2,006(22.97 \%)$ & 4,080 & $86(19.15 \%)$ & 104 \\
\hline Systemic corticosteroids (IV or PO) & $120(1.37 \%)$ & 256 & $207(46.1 \%)$ & 473 \\
\hline Oral corticosteroids & $120(1.37 \%)$ & 256 & $16(3.56 \%)$ & 19 \\
\hline Intravenous corticosteroids & $0(0 \%)$ & 0 & $202(44.99 \%)$ & 465 \\
\hline Ambroxol+SABA & $16(0.18 \%)$ & 17 & $2(0.45 \%)$ & 2 \\
\hline Antihistamines & $711(8.14 \%)$ & 878 & $33(7.35 \%)$ & 39 \\
\hline Anti-lgE & $0(0 \%)$ & 0 & $0(0 \%)$ & 0 \\
\hline Mast cell stablizers & $326(3.73 \%)$ & 409 & $24(5.35 \%)$ & 26 \\
\hline Inhaled corticosteroids nasal spray & $349(4 \%)$ & 430 & $5(1.11 \%)$ & 5 \\
\hline Antitussive & $68(0.78 \%)$ & 83 & $11(2.45 \%)$ & 13 \\
\hline Systemic antibiotics & $1,230(14.09 \%)$ & 2,133 & $260(57.91 \%)$ & 660 \\
\hline Local antibiotics & $160(1.83 \%)$ & 198 & $56(12.47 \%)$ & 61 \\
\hline Immune modulator (Thymopolypeptide/Interferon) & $25(0.29 \%)$ & 46 & $15(3.34 \%)$ & 18 \\
\hline Chinese herbal medicine & $4,228(48.42 \%)$ & 10,407 & $163(36.3 \%)$ & 214 \\
\hline Chinese patent medicine & $4738(54.26 \%)$ & 10,340 & $176(39.2 \%)$ & 223 \\
\hline $\begin{array}{l}\text { ICS: Inhaled corticosteroids; LABA: Long-acting beta } \\
\text { combination inhaler; SABA: Short-acting beta-agoni } \\
\text { Sustained-release; IV: Intravenous; PO: Oral }\end{array}$ & $\begin{array}{l}\text { gonists; LAMA: } \\
\text {; SAMA: Short-c }\end{array}$ & $\begin{array}{l}\text { g-acting muscarinic } \\
\text { ng muscarinic antag }\end{array}$ & $\begin{array}{l}\text { tagonists; ICS/L } \\
\text { ists; IR: Immedia }\end{array}$ & $\begin{array}{l}\text { A: An ICS and LABA } \\
\text { elease; SR: }\end{array}$ \\
\hline
\end{tabular}

\section{Patients receiving TCM and western medicine for asthma management}

Of the identified asthma patients, 8,877 patients received TCM, of which $6(0.07 \%)$ had physician office visits that did not specify the department they visited; 3,237 patients were managed by western medicine (Table 2). Prescription filling records were found in 3,212 patients, out of which 3,160 took medications for stable asthma. A total of 282 patients took medications for acute asthma exacerbations. 
ICSLABA was prescribed in 1,365 (43.2\%) patients with stable asthma and $75(26.6 \%)$ patients with asthma exacerbations, respectively. LTRA was used in 900 (28.48\%) patients with stable asthma and 51 (18.09\%) patients with acute asthma exacerbations (Table 3).

Table 2

Patients receiving TCM and Western Medicine

\begin{tabular}{|lllll|}
\hline & Total & TCM & Western Medicine & N/A \\
\hline Number of Patients & 8877 & $5766(64.95 \%)$ & $3237(36.47 \%)$ & $6(0.07 \%)$ \\
\hline Number of Office Visits & 26027 & $17429(66.97 \%)$ & $8589(33 \%)$ & $9(0.03 \%)$ \\
\hline
\end{tabular}


Table 3

Medication use in asthma patients treated with western medicine

\begin{tabular}{|c|c|c|c|c|}
\hline & \multicolumn{2}{|l|}{ Stable Asthma } & \multicolumn{2}{|c|}{ Acute Asthma Exacerbations } \\
\hline & No. of patients & No. of prescriptions & No. of patients & No. of prescriptions \\
\hline Patient Numbers & 3,160 & $7,552^{\mathrm{a}}$ & 282 & 734 \\
\hline Total ICS Prescriptions & $453(14.34 \%)$ & 719 & $66(23.4 \%)$ & 112 \\
\hline ICS combination therapy ${ }^{a}$ & $18(0.57 \%)$ & 21 & $13(4.61 \%)$ & 13 \\
\hline ICS monotherapy & $437(13.83 \%)$ & 698 & $56(19.86 \%)$ & 99 \\
\hline ICS/LABA & $1,365(43.2 \%)$ & 2,626 & $75(26.6 \%)$ & 97 \\
\hline LAMA & $72(2.28 \%)$ & 121 & $6(2.13 \%)$ & 9 \\
\hline LABA & $8(0.25 \%)$ & 8 & $3(1.06 \%)$ & 3 \\
\hline SABA & $473(14.97 \%)$ & 946 & $65(23.05 \%)$ & 112 \\
\hline SAMA & $31(0.98 \%)$ & 88 & $3(1.06 \%)$ & 3 \\
\hline SAMA+SABA & $40(1.27 \%)$ & 53 & $21(7.45 \%)$ & 27 \\
\hline Theophylline IR & $117(3.7 \%)$ & 174 & $152(53.9 \%)$ & 513 \\
\hline Theophylline SR & $16(0.51 \%)$ & 37 & $3(1.06 \%)$ & 3 \\
\hline Theophylline IV & $0(0 \%)$ & 0 & $150(53.19 \%)$ & 510 \\
\hline LTRA & $900(28.48 \%)$ & 1,829 & $51(18.09 \%)$ & 61 \\
\hline Systemic corticosteroids (IV or PO) & $55(1.74 \%)$ & 114 & $135(47.87 \%)$ & 368 \\
\hline Oral corticosteroids & $55(1.74 \%)$ & 114 & $8(2.84 \%)$ & 10 \\
\hline Intravenous corticosteroids & $0(0 \%)$ & 0 & $134(47.52 \%)$ & 365 \\
\hline Ambroxol+SABA & $7(0.22 \%)$ & 7 & $2(0.71 \%)$ & 2 \\
\hline Antihistamines & $445(14.08 \%)$ & 557 & $20(7.09 \%)$ & 23 \\
\hline Anti-lgE & $0(0 \%)$ & 0 & $0(0 \%)$ & 0 \\
\hline Mast cell stablizers & $51(1.61 \%)$ & 89 & $8(2.84 \%)$ & 10 \\
\hline Inhaled corticosteroids nasal spray & $219(6.93 \%)$ & 256 & $4(1.42 \%)$ & 4 \\
\hline Antitussives & $49(1.55 \%)$ & 62 & $10(3.55 \%)$ & 12 \\
\hline Systemic antibiotics & $646(20.44 \%)$ & 998 & $161(57.09 \%)$ & 517 \\
\hline Local antibiotics & $97(3.07 \%)$ & 124 & $21(7.45 \%)$ & 24 \\
\hline $\begin{array}{l}\text { Immune modulator } \\
\text { (Thymopolypeptide/Interferon) }\end{array}$ & $10(0.32 \%)$ & 19 & $6(2.13 \%)$ & 8 \\
\hline Chinese herbal medicine & $402(12.72 \%)$ & 938 & $78(27.66 \%)$ & 111 \\
\hline Chinese patent medicine & $1,171(37.06 \%)$ & 2,281 & $81(28.72 \%)$ & 112 \\
\hline $\begin{array}{l}\text { ICS: Inhaled corticosteroids; LABA: L } \\
\text { combination inhaler; SABA: Short-ac } \\
\text { Sustained-release; IV: Intravenous; P }\end{array}$ & $\begin{array}{l}\text { ting beta-agonists } \\
\text { ta-agonists; SAM }\end{array}$ & $\begin{array}{l}\text { AMA: Long-acting mu } \\
\text { hort-acting muscarin }\end{array}$ & $\begin{array}{l}\text { hic antagonists; I } \\
\text { agonists; IR: Imm }\end{array}$ & $\begin{array}{l}\text { ABA: An ICS and LABA } \\
\text { te release; SR: }\end{array}$ \\
\hline
\end{tabular}

\section{Prescription counts and numbers of asthma exacerbations}

A gradual increase in total prescription counts was identified during the study period. Thirteen prescriptions were recorded from 2011 to 2012, including 2 (15.38\%) ICS/LABA, 7 (53.85\%) SABA, and 11 (84.62\%) Chinese patent medicine prescriptions. During 2018 and 2019 , a 
total of 1,481 prescriptions were documented, including 23 (1.55\%) ICS, 663 (44,77\%) ICS/LABA, 384 (25.93\%) LTRA, 137 (9.25\%) SABA, and 353 (23.84\%) Chinese patent medicine prescriptions (Table 3). The increase in ICS/LABA and LTRA use were similar. A decrease in prescriptions counts was found in SABA and Chinese patent medicine. From 2011 to 2012, 21 (1.9\%) asthma exacerbations and 14 (3.56\%) patients experienced exacerbations were identified. From 2018 to 2019, 155 (4.55\%) asthma exacerbations and 59 (3.61\%) patients had exacerbations were diagnosed (Table 4).

Table 4

Prescription counts in patients receiving western medicine for asthma management

\begin{tabular}{|c|c|c|c|c|c|c|c|c|}
\hline Year & Total & $\begin{array}{l}\text { ICS } \\
\text { monotherapy }\end{array}$ & ICS/LABA & LTRA & SABA & $\begin{array}{l}\text { Systemic } \\
\text { antibiotics }\end{array}$ & $\begin{array}{l}\text { Local } \\
\text { antibiotics }\end{array}$ & $\begin{array}{l}\text { Chinese } \\
\text { patent } \\
\text { medicine }\end{array}$ \\
\hline $\begin{array}{l}2011- \\
2012\end{array}$ & 13 & $0(0 \%)$ & $2(15.38 \%)$ & $0(0 \%)$ & $7(53.85 \%)$ & $2(15.38 \%)$ & $0(0 \%)$ & $11(84.62 \%)$ \\
\hline $\begin{array}{l}2012- \\
2013\end{array}$ & 42 & $0(0 \%)$ & $5(11.9 \%)$ & $1(2.38 \%)$ & $3(7.14 \%)$ & $4(9.52 \%)$ & $0(0 \%)$ & $16(38.1 \%)$ \\
\hline $\begin{array}{l}2013- \\
2014\end{array}$ & 614 & $5(0.81 \%)$ & $91(14.82 \%)$ & $97(15.8 \%)$ & $136(22.15 \%)$ & $201(32.74 \%)$ & $11(1.79 \%)$ & 196(31.92\%) \\
\hline $\begin{array}{l}2014- \\
2015\end{array}$ & 1,268 & $15(1.18 \%)$ & $321(25.32 \%)$ & $283(22.32 \%)$ & $174(13.72 \%)$ & $189(14.91 \%)$ & $15(1.18 \%)$ & $415(32.73 \%)$ \\
\hline $\begin{array}{l}2015- \\
2016\end{array}$ & 1,519 & $19(1.25 \%)$ & $503(33.11 \%)$ & $349(22.98 \%)$ & $194(12.77 \%)$ & $271(17.84 \%)$ & $22(1.45 \%)$ & $470(30.94 \%)$ \\
\hline $\begin{array}{l}2016- \\
2017\end{array}$ & 1,673 & $21(1.26 \%)$ & $544(32.52 \%)$ & $399(23.85 \%)$ & $195(11.66 \%)$ & $275(16.44 \%)$ & $32(1.91 \%)$ & $484(28.93 \%)$ \\
\hline $\begin{array}{l}2017- \\
2018\end{array}$ & 1,676 & $29(1.73 \%)$ & $594(35.44 \%)$ & $377(22.49 \%)$ & $212(12.65 \%)$ & $342(20.41 \%)$ & $39(2.33 \%)$ & $448(26.73 \%)$ \\
\hline $\begin{array}{l}2018- \\
2019\end{array}$ & 1,481 & $23(1.55 \%)$ & $663(44.77 \%)$ & $384(25.93 \%)$ & $137(9.25 \%)$ & $231(15.6 \%)$ & $29(1.96 \%)$ & $353(23.84 \%)$ \\
\hline 吅 & 8,286 & $112(1.35 \%)$ & $2,723(32.86 \%)$ & $1,890(22.81 \%)$ & $1,058(12.77 \%)$ & $1,515(18.28 \%)$ & $148(1.79 \%)$ & 2,393(28.88\%) \\
\hline
\end{tabular}

Table 5

Number of asthma exacerbations and number of patients with asthma exacerbations

\begin{tabular}{|lll|}
\hline Year & Number of asthma exacerbations $(\%)$ & Number of patients with asthma exacerbations (\%) \\
\hline $2011-2012$ & $21(1.9 \%)$ & $14(3.56 \%)$ \\
\hline $2012-2013$ & $32(1.98 \%)$ & $20(3.97 \%)$ \\
\hline $2013-2014$ & $146(6.16 \%)$ & $40(6.79 \%)$ \\
\hline $2014-2015$ & $132(3.29 \%)$ & $70(5.93 \%)$ \\
\hline $2015-2016$ & $167(3.71 \%)$ & $83(5.98 \%)$ \\
\hline $2016-2017$ & $182(3.44 \%)$ & $99(6.49 \%)$ \\
\hline $2017-2018$ & $199(5.34 \%)$ & $88(5.29 \%)$ \\
\hline $2018-2019$ & $155(4.55 \%)$ & $59(3.61 \%)$ \\
\hline Total & 1034 & 473 \\
\hline
\end{tabular}

\section{Discussion}

There is a sharp increase in asthma prevalence since the 1960s, especially in developed countries[4]. It was proposed that decreased exposure to house dust, mites, fungi, and other unhygienic environments in the developed country contributes to the increasing number of asthma patients[19]. As expected, our study highlights the increase in total prescription counts per year and the number of patients with asthma exacerbations. However, the rise in physician-identified patients and the implementation of electronic medical records can also contribute to the increase in our findings. 
In this retrospective, real-world analysis, we demonstrated the prevalence of different medications used for asthma management in China. ICS is part of the first-line therapy in asthma, regardless of disease severity. It is delivered directly into the lungs, thus, limiting the systemic adverse effects of corticosteroids[20]. The underuse of ICS may be due to poor adherence, intolerable side effects, contraindications, and concerns for increased risk of pneumonia, especially in patients with mild or moderate asthma. Over half of the cohort uses ICS for stable asthma. ICS-containing medications were prescribed to $44.66 \%$ of patients with stable asthma, similar to ICS uses in the U.K. and the U.S, both over $40 \%[21,22]$, and much higher than those in Japan and Korea, which were around 10\% [23]. This proportion is also higher than $10.2 \%$ reported by Huang, et al in patients with physician-diagnosed asthma[6]. The conflicting results of ICS use may be due to the changes in the guidelines, the perceptions of long-term steroid use, and the transformation of hand-written medical records to electronic data.

According to the GINA report, ICS/LABA is recommended in almost all adult asthma patients. Regular use of ICS and LABA allows a lower dose of ICS, improves symptom management, and reduces the risk of exacerbations[24]. In addition, the combination is more effective than ICS+LTRA[25]. In our study, ICS/LABA was the most frequently prescribed medication (33.67\%) to patients with stable asthma, much lower than $90.2 \%$ of patients in the INITIAL study[26]. There was a significantly decreased risk of exacerbations $(P<0.05)$ in patients using ICS+LTRA. Our finding is consistent with earlier studies regarding the benefits of ICS/LABA[24, 27-29].

LTRA improves asthma control and reduces the frequency of asthma exacerbations, but is less effective than ICS[30]. Therefore, LTRA is listed by the guidelines as an alternative add-on in patients with moderate or severe asthma. LTRA is the second most prescribed medication in our cohort (22.97\%). However, LTRA did not show significant benefit in preventing exacerbations in this study.

In our cohort, over $60 \%$ of patients received TCM management. Though the exact mechanisms of TCM are still unclear, it has shown some effects in anti-inflammation, airway relaxation, and reducing airway hypersensitivity[31]. TCM, used as adjuvant therapy, can reduce asthma symptoms, enhance patients' lung function, and improve the quality of life, but the treatment effects were limited and may not reduce the risk of exacerbations[31,32]. Our study showed a continuous decrease in TCM use over the years while increasing use of western medicine, which may be explained by the implementation of the guidelines or the limited efficacy of TCM in patients with moderate to severe asthma.

The GINA report recommends using SABA, oxygen, intravenous corticosteroids, and ICS for managing exacerbations. Other studies showed that $87 \%$ to $92.24 \%$ of patients with asthma exacerbation received ICS or ICS/LABA or ICS/LABA[33, 34]. In the current study, systemic antibiotics $(57.91 \%)$, systemic corticosteroids $(46.1 \%)$, and theophylline $(51.45 \%)$ were frequently prescribed to patients with asthma exacerbations. The rate $(51.45 \%)$ of theophylline use during acute exacerbations of asthma, which is comparable to theophylline application in the UK[35]. Theophylline reduces days of hospitalizations but is not as effective as SABA in improving lung functions in acute settings[36]. In addition, theophylline requires frequent blood concentration monitoring to avoid toxicity. It is no longer recommended due to its poor efficacy and safety profile.

\section{Strengths and Limitations}

To our knowledge, this is the largest retrospective observational cohort study evaluating real-world prescribing patterns of asthma medications in China. It is also the first one that includes both western medicine and TCM for asthma management, and changes in asthma medication use over time. The study has several limitations. First, the data extraction was based on the medical encounters recorded in the data platform. Office visits and prescriptions that were in paper-based records were not included which might account for the lower proportion of patients receiving each medication. Changes in medications in patients did not experience exacerbations, and medication adherence was also not analyzed in the study. Due to the nature of retrospective observational design, the strength and frequency of medication were decided by physicians. In addition, it is unclear why each medication was prescribed. Lastly, the specific TCM prescribed was not included in the study, thus the effect of TCM in addition to western medicine on asthma management cannot be determined.

\section{Conclusions}

Our study suggests that more asthma patients in China were managed with TCM than western medicine. In those managed with western medicine, there are gaps between practical medication management and guideline recommendations, partly due to the study design and physicians' perspectives of asthma management. The study provided valuable insight into clinical practices of asthma management in China. Whether TCM reduced the rate of asthma exacerbation requires further investigation. National and regional efforts are necessary to improve the medication selections for patients with asthma.

\section{Abbreviations}


GINA

Global Initiative for Asthma

ICS

Inhaled corticosteroids

ICS/LABA

An ICS and LABA combination inhaler

IR

Immediate release

IV

Intravenous

LABA

Long-acting beta agonists

LAMA

Long-acting muscarinic antagonists

$\mathrm{PO}$

OralSABA:Short-acting beta agonists

SAMA

Short-acting muscarinic antagonists

SR

Sustained-release

TCM

Tradition Chinese medicine

\section{Declarations}

\section{Ethics approval and consent to participate}

The authors are accountable for all aspects of the work in ensuring that questions related to the accuracy or integrity of any part of the work are appropriately investigated and resolved. The study was conducted in accordance with the Declaration of Helsinki (as revised in 2013). This study was approved by the Committee on Ethics of Jinan Central Hospital affiliated to Shandong First Medical University, Shandong (No. JCH2020-136-01). Patient consents were waived due to retrospective study design.

\section{Consent for publication}

Not applicable.

\section{Availability of data and materials}

The datasets used and/or analyzed during the current study are available from the corresponding author on reasonable request.

\section{Competing interests}

The authors declare that they have no competing interests that could have influenced the present study.

\section{Funding}

This work was supported by Shandong Provincial Natural Science Foundation (ZR2020QH003, ZR2020MH005, ZR2021ZD35), Jinan Science and Technology Plan (202019064), Shandong Provincial Medical and Health Science and Technology Development Plan Project(2019WS475), and Shandong Provincial Postdoctoral Innovation Project(202003008).

\section{Authors' contributions}

(I) Conception and design: Shujuan Jiang, Chunyan Xing

(II) Administrative support: Jian Sun

(III) Provision of study materials or patients: Jian Sun 
(IV) Collection and assembly of data: Xin Wang, Xiaobin Ma, Yuyu Feng, Yajun Wang, Junren Wang

(V) Data analysis and interpretation: Jian Sun

(VI) Manuscript writing: All authors

(VII) Final approval of manuscript: All authors

Acknowledgements

We are particularly indebted to Jinan Health Medical Big Data Platform, administered by Shandong Health Medical Big Data Co., Ltd.

Footnotes

Trialregistration:ChineseClinicalTrialRegistry,ChiCTR2100053610,Registered21November2021http://www.chictr.org.cn/showproj.aspx? proj=66131

\section{References}

1. Mims JW: Asthma: definitions and pathophysiology. Int Forum Allergy Rhinol 2015, 5 Suppl 1:S2-6.

2. Quirt J, Hildebrand KJ, Mazza J, Noya F, Kim H: Asthma. Allergy Asthma Clin Immunol 2018, 14:50.

3. Kansen HM, Le TM, Meijer Y, Uiterwaal C, Knulst AC, van der Ent CK, van Erp FC: Perceived triggers of asthma impair quality of life in children with asthma. Clin Exp Allergy 2019, 49:980-989.

4. Dharmage SC, Perret JL, Custovic A: Epidemiology of Asthma in Children and Adults. Front Pediatr 2019, 7:246.

5. Asthma [https://www.who.int/news-room/fact-sheets/detail/asthma]

6. Huang K, Yang T, Xu J, Yang L, Zhao J, Zhang X, Bai C, Kang J, Ran P, Shen H, et al: Prevalence, risk factors, and management of asthma in China: a national cross-sectional study. Lancet 2019, 394:407-418.

7. Mukherjee M, Stoddart A, Gupta RP, Nwaru BI, Farr A, Heaven M, Fitzsimmons D, Bandyopadhyay A, Aftab C, Simpson CR, et al: The epidemiology, healthcare and societal burden and costs of asthma in the UK and its member nations: analyses of standalone and linked national databases. BMC Med 2016, 14:113.

8. Kerkhof M, Tran TN, Soriano JB, Golam S, Gibson D, Hillyer EV, Price DB: Healthcare resource use and costs of severe, uncontrolled eosinophilic asthma in the UK general population. Thorax 2018, 73:116-124.

9. Ivanova JI, Bergman R, Birnbaum HG, Colice GL, Silverman RA, McLaurin K: Effect of asthma exacerbations on health care costs among asthmatic patients with moderate and severe persistent asthma. J Allergy Clin Immuno/ 2012, 129:1229-1235.

10. Castillo JR, Peters SP, Busse WW: Asthma Exacerbations: Pathogenesis, Prevention, and Treatment. J Allergy Clin Immunol Pract 2017, 5:918-927.

11. Busse WW, Pedersen S, Pauwels RA, Tan WC, Chen YZ, Lamm CJ, O'Byrne PM, Group SI: The Inhaled Steroid Treatment As Regular Therapy in Early Asthma (START) study 5-year follow-up: effectiveness of early intervention with budesonide in mild persistent asthma. J Allergy Clin Immunol 2008, 121:1167-1174.

12. O'Byrne PM, Pedersen S, Lamm CJ, Tan WC, Busse WW, Group SI: Severe exacerbations and decline in lung function in asthma. Am J Respir Crit Care Med 2009, 179:19-24.

13. Global Strategy for Asthma Management and Prevention [https://www.ginasthma.org/]

14. Expert Panel Working Group of the National Heart L, Blood Institute a, coordinated National Asthma E, Prevention Program Coordinating C, Cloutier MM, Baptist AP, Blake KV, Brooks EG, Bryant-Stephens T, DiMango E, et al: 2020 Focused Updates to the Asthma Management Guidelines: A Report from the National Asthma Education and Prevention Program Coordinating Committee Expert Panel Working Group. J Allergy Clin Immunol 2020, 146:1217-1270.

15. Price D, Haughney J, Sims E, Ali M, von Ziegenweidt J, Hillyer EV, Lee AJ, Chisholm A, Barnes N: Effectiveness of inhaler types for realworld asthma management: retrospective observational study using the GPRD. J Asthma Allergy 2011, 4:37-47.

16. Hurtado I, Garcia-Sempere A, Peiro S, Bengoetxea A, Prieto JL, Sanfelix-Gimeno G: Real-World Patterns of Pharmacotherapeutic Management of Asthma Patients With Exacerbations in the Spanish National Health System. Front Pharmacol $2020,11: 1323$.

17. Cho EY, Oh KJ, Rhee CK, Yoo KH, Kim BY, Bae HW, Lee BJ, Choi DC, Lee H, Park HY: Comparison of clinical characteristics and management of asthma by types of health care in South Korea. J Thorac Dis 2018, 10:3269-3276. 
18. Serhal S, Saini B, Bosnic-Anticevich S, Krass I, Wilson F, Armour C: Medication Adherence in a Community Population with Uncontrolled Asthma. Pharmacy (Basel) 2020, 8.

19. Strachan DP: Hay fever, hygiene, and household size. BMJ 1989, 299:1259-1260.

20. Barnes PJ, Pedersen S: Efficacy and safety of inhaled corticosteroids in asthma. Report of a workshop held in Eze, France, October 1992. Am Rev Respir Dis 1993, 148:S1-26.

21. Bengtson LGS, Yu Y, Wang W, Cao F, Hulbert EM, Wolbeck R, Elliott CA, Buikema AR: Inhaled Corticosteroid-Containing Treatment Escalation and Outcomes for Patients with Asthma in a U.S. Health Care Organization. J Manag Care Spec Pharm 2017, 23:1149-1159.

22. Bloom Cl, Saglani S, Feary J, Jarvis D, Quint JK: Changing prevalence of current asthma and inhaled corticosteroid treatment in the UK: population-based cohort 2006-2016. Eur Respir J 2019, 53.

23. Inoue H, Milligan KL, McConnon A, Yoshisue H, Loefroth E, McSharry M, Yokoyama A, Ichinose M: Uncontrolled asthma: a retrospective cohort study in Japanese patients newly prescribed with medium-/high-dose ICS/LABA. NPJ Prim Care Respir Med 2021, 31:12.

24. Greening AP, Ind PW, Northfield M, Shaw G: Added salmeterol versus higher-dose corticosteroid in asthma patients with symptoms on existing inhaled corticosteroid. Allen \& Hanburys Limited UK Study Group. Lancet 1994, 344:219-224.

25. Lemanske RF, Jr., Mauger DT, Sorkness CA, Jackson DJ, Boehmer SJ, Martinez FD, Strunk RC, Szefler SJ, Zeiger RS, Bacharier LB, et al: Step-up therapy for children with uncontrolled asthma receiving inhaled corticosteroids. N Engl J Med 2010, 362:975-985.

26. Lin J, Fu X, Jiang P, Song W, Hu X, Jie Z, Liu C, He Z, Zhou X, Tang H: Post hoc analysis of initial treatments and control status in the INITIAL study: an observational study of newly diagnosed patients with asthma. BMC Pulm Med 2020, 20:87.

27. Giembycz MA, Kaur M, Leigh R, Newton R: A Holy Grail of asthma management: toward understanding how long-acting beta(2)adrenoceptor agonists enhance the clinical efficacy of inhaled corticosteroids. Br J Pharmaco/ 2008, 153:1090-1104.

28. Shrewsbury S, Pyke S, Britton M: Meta-analysis of increased dose of inhaled steroid or addition of salmeterol in symptomatic asthma (MIASMA). BMJ 2000, 320:1368-1373.

29. O'Byrne PM, Barnes PJ, Rodriguez-Roisin R, Runnerstrom E, Sandstrom T, Svensson K, Tattersfield A: Low dose inhaled budesonide and formoterol in mild persistent asthma: the OPTIMA randomized trial. Am J Respir Crit Care Med 2001, 164:1392-1397.

30. Busse W, Raphael GD, Galant S, Kalberg C, Goode-Sellers S, Srebro S, Edwards L, Rickard K, Fluticasone Proprionate Clinical Research Study G: Low-dose fluticasone propionate compared with montelukast for first-line treatment of persistent asthma: a randomized clinical trial. J Allergy Clin Immunol 2001, 107:461-468.

31. Li XM, Brown L: Efficacy and mechanisms of action of traditional Chinese medicines for treating asthma and allergy. $J$ Allergy Clin Immunol 2009, 123:297-306; quiz 307-298.

32. Li ZY, Tian CY, Wang XH, Liu YF: Effectiveness of Chinese herbal medicine Ping Chuan Ke Li for the management of mild/moderate persistent asthma. Medicine (Baltimore) 2018, 97:e12829.

33. Yan BD, Meng SS, Ren J, Lv Z, Zhang QH, Yu JY, Gao R, Shi CM, Wu CF, Liu CL, et al: Asthma control and severe exacerbations in patients with moderate or severe asthma in Jilin Province, China: a multicenter cross-sectional survey. BMC Pulm Med 2016, 16:130.

34. Jayadeva BT, Panchaksharimath P: A retrospective study on drug utilization in patients with acute exacerbation of bronchial asthma in adults at a tertiary teaching hospital in Bengaluru. Egyptian Journal of Chest Diseases and Tuberculosis 2016, 65:19-22.

35. Bloom Cl, de Preux L, Sheikh A, Quint JK: Health and cost impact of stepping down asthma medication for UK patients, 2001-2017: A population-based observational study. PLoS Med 2020, 17:e1003145.

36. Mahemuti G, Zhang H, Li J, Tieliwaerdi N, Ren L: Efficacy and side effects of intravenous theophylline in acute asthma: a systematic review and meta-analysis. Drug Des Devel Ther 2018, 12:99-120. 